\title{
Study of the Vibration Transmission and Path Recognition of an Underground Powerhouse Using Energy Finite Element Method
}

\author{
Wei $\mathrm{Xu}^{1,2}$ and Zhen-yue $\mathrm{Ma}^{1}$ \\ ${ }^{1}$ School of Civil and Hydraulic Engineering, Dalian University of Technology, Dalian, Liaoning 116024, China \\ ${ }^{2}$ College of Water Resource, Shenyang Agricultural University, Shenyang, Liaoning 110866, China \\ Correspondence should be addressed to Wei Xu; dlutxw@sina.com
}

Received 19 August 2015; Revised 7 October 2015; Accepted 15 October 2015

Academic Editor: Marcello Vanali

Copyright (C) 2016 W. Xu and Z.-y. Ma. This is an open access article distributed under the Creative Commons Attribution License, which permits unrestricted use, distribution, and reproduction in any medium, provided the original work is properly cited.

\begin{abstract}
Taking the underground powerhouse of a pumped storage power station as the engineering background, this study established a 3D finite element model of the main and auxiliary powerhouse and performed the dynamic harmonica calculation for its fluctuating pressure. Based on the power flow theory, the ANSYS Parametric Design Language (APDL) procedure was completed to calculate the power transmission in the powerhouse. The law of dominant path recognition was first proposed to assess the structure's dominant transmission using a numerical solution on nodes in the model. The conductivity of the closed-cell foam that filled the structure's joints was examined, as were the dynamic transmission features of the rock around and beneath the powerhouse. The results indicated that, as a structural joint filler, closed-cell foam could actively restrict vibration transmission, and the directions of dynamic transmission were mainly perpendicular to and along the river in the foundation rock. Approximately 20 percent of the foundation rock beneath the auxiliary powerhouse was disturbed by the concrete around the spiral case and induced vibrations in the powerhouse's lower floors. Vibration in the higher floors was derived from downstream rock, and the dynamic transmission effect had a clear advantage along the horizontal direction.
\end{abstract}

\section{Introduction}

Underground powerhouses have many advantages compared to other types of powerhouses, including safety and freedom from external disturbances, so they are used widely around the world. Considering the need for management and repairs, auxiliary powerhouses are always arranged underground and close to the main powerhouses, forming a unified structure of both powerhouses. When running turbine machines, the auxiliary powerhouse absorbs the vibration energy from the main powerhouse. This energy may induce local resonance on the auxiliary powerhouse floors and walls, harming the equipment and other aspects of the structure $[1,2]$. Up to now, a number of studies have been made on the vibration of powerhouse structure under pressure fluctuation, but most of them only examined stress and displacement of the main powerhouses $[3,4]$; there were less related researches on auxiliary powerhouse and on the path of vibration transmission. The harmonic calculation in dynamic analysis is the primary method used to analyse complex structures, but the transmission function achieved by a structural frequency response cannot reflect all of the information on a vibratory transmission path. Therefore, harmonic calculations cannot directly identify vibration transmission paths and, as a result, there are no reasonable measures in place for the dangers caused by structural vibrations. Recently, researchers $[5,6]$ studied vibration power flow and its application on the passenger car for identification of vibration transmission path; the results showed that the method could reduce the structure-borne noise level about $5 \mathrm{dBA}$. Vander et al. [7] focused on vibration transmissions with single excitation and multipoint impact in a car. De Klerk and Rixen [8] proposed a component transfer path analysis procedure based on frequency response functions for test bench dynamics. Le Bot and Bou Chakra [9] presented an experiment to measure the dependence of friction noise versus the nominal contact area. They found that the vibration energy was proportional to the contact area sometimes, but on the other hand the vibration energy was constant. Renno and Mace [10] calculated the reflection and transmitting coefficients of the joints by 
coupling finite element with a wave and finite element, and they considered the wave travelling in the structure. Wang et al. [11] investigated the natural frequencies and mode shapes of structures with mixed random and interval parameters by using a hybrid stochastic and interval approach; the examples showed that the method could be also applicable to solve pure random and pure interval problems. Besides, power flow method has also been widely applied in other aspects, for examples, beam structures [12], flexible manipulator [13], powertrain [14], complex frame structure [15], compress system [16], and electric vehicle [17].

Although there are not so many research results for the underground houses, there are many underground hydropower houses in China, so our team is always studying this point. For example, Zhi and Ma [18, 19] have performed a contrastive analysis on a numerical vibratory model of an underground powerhouse, while the work of Xu et al. [20] is focusing on using power flow theory and the energy finite element method (EFEM) to analyse the response of main powerhouse's vibrations by fluctuating pressure in a spiral case.

Using the theory of multidegree of freedom vibration transmission, this study investigated the power transmission in a hydropower house and the surrounding rock with hydraulic fluctuating pressure in a spiral case and a draft tube under normal operation. This study addressed questions related to energy distribution properties and energy transmission between the main and auxiliary powerhouses. The concept of a dominant power threshold value (DPTV) was defined for a concrete structure using the universality of power transmission and its probability distribution, and the law of dominant path recognition based on EFEM was proposed to provide an effective method of recognising structural dynamic transmission paths. The results would be helpful in further studies on dynamic transmission properties from a vibration source and the transmission path and in establishing a theoretical foundation for vibration isolation and dumping in hydropower house. The research in this paper could provide a reference method for recognising dynamic transmission paths in damaged structures.

\section{Basic Theory}

2.1. Power Flow Theory and Power Flow FEM. Power is defined as the work performed by a dynamic load within the $i$ th node interval, as described by

$$
P_{i}=F_{i} \cdot V_{i}
$$

where $F_{i}$ and $V_{i}$ are the force and velocity, respectively.

Power can reflect not only the combined features of a force and its structural response but also structural impedance characteristics. Therefore, power flow plays an important role in structural vibration transmissions when assessing power transmission paths in complex constructions. In order to emphasize the process of power transmission, the process of power transmission can be as power flow. So power flow means power transmission in structures.
If a load can be simplified as a harmonic load, its structural response velocity is also presented as a series of harmonic changes. Therefore, the function can be represented by (2) when calculating the power flow in a cycle as follows:

$$
\begin{aligned}
P_{i} & =\frac{1}{T} \int_{0}^{T}\left|F_{i}\right| \cos \omega t \cdot\left|V_{i}\right| \cos (\omega t+\phi) d t \\
& =\frac{1}{2}\left|F_{i}\right| \cdot\left|V_{i}\right| \cdot \cos \phi
\end{aligned}
$$

where $P_{i}$ is the effective value of power flow in one cycle, $F_{i}$ is the harmonic load (a complex vector), $V_{i}$ is velocity of a point in the structure (also a complex vector), $\omega$ is the angular frequency of the simple harmonic vibration, and $\phi$ means the phase angle of the velocity and load.

Manipulating (2) with complex operation when $F_{i}$ and $V_{i}$ are expressed by complex vector, $P_{i}$ can be showed as expression in

$$
P_{i}=\frac{1}{2} \operatorname{Re}\left\{F_{i} \cdot V_{i}^{*}\right\}=\frac{1}{2} \operatorname{Re}\left\{F_{i}^{*} \cdot V_{i}\right\}
$$

where the symbol " $*$ " represents a conjugate vector and the structural power flow transmission can be obtained by a theoretical derivation or experiment. Here if the excited load $F_{i}$ is the force, then $P_{i}$ is power flow in time domain, while the load on the structure is defined as a force spectral density, and then $P_{i}$ can be expressed by $P(\omega)$ in frequent domain, where $\omega$ means frequency and $P(\omega)$ is the power flow spectral density.

Based on finite element method, the dynamic equation can be expressed as

$$
\{U\}=\left([K]+j \omega[C]-\omega^{2}[M]\right)^{-1}\{F\},
$$

where $[K]$ is stiffness matrix, $[C]$ is damping matrix, $[M]$ is mass matrix, $\{U\}$ is the vector composed by nodes' displacement, $\{F\}$ is a vector composed by nodes' force, and $\omega$ and $j$ are frequency and imaginary symbol, respectively.

By differentiating (4) with respect to the time, node velocity $V$ can be expressed by (5) in frequent domain as follows:

$$
V=-j \omega U
$$

where $V$ is the node velocity and other symbols are shown as mentioned above.

Substituting (5) into (3) yields (6), and power flow $P_{i}$ on node $i$ can be obtained as follows:

$$
P_{i}=\frac{1}{2} \operatorname{Re}\left\{F_{i} \cdot V_{i}^{*}\right\}=-\frac{\omega_{i}}{2} \operatorname{Im}\left\{F_{i} \cdot U_{i}^{*}\right\}
$$

where Re and Im are the real part and the imaginary part of the variables, respectively.

2.2. Transmission Path Recognition. The dynamic transmission effect exists generally in a complex $3 \mathrm{D}$ model, but a method for identifying a 3D transmission path for underground hydropower station projects is much more difficult than other industrial projects. It is known that there are three 
types of dynamic loadings in hydropower station, hydraulic loading, mechanics loading, and electromagnetic loading. When they are inspired by high-pressure water in spiral case, hydroturbine, and generator (vibration sources), the hydroenergy changed to electric energy and at the same time the hydropower plant vibrates and the vibration transmits to other parts, such as the auxiliary powerhouse. From the vibration sources to the auxiliary powerhouse there will be many paths for power flow transmission, and it is very important to search the main paths and weaken the vibration of the auxiliary powerhouse by taking effective vibration reducing measure. This section describes the concept of a dominant power threshold value (DPTV) and confirms the law of dominant path recognition.

(1) Dominant Power Threshold Value. Based on the theory of a significance test in mathematical statistics, (7) is the discriminate of the main transmission path for structural vibrations:

$$
P\left\{p_{i}>K_{\alpha}\right\}=1-\alpha
$$

where $p_{i}$ represents the power flow at a node of the finite element model, the meaning of symbol $P$ is the probability, $K_{\alpha}$ is a constant $\left(K_{\alpha}>0\right), \alpha$ denotes the significant factor, and $1-\alpha$ represents the probability.

Using the intermediate value theory, it can be confirmed that $K_{\alpha}$ must exist within the transmission region to satisfy (7), and $K_{\alpha}$ is the power flow value at a specific node, so $K_{\alpha}$ can be defined as the DPTV in this equation.

(2) Law of Dominant Path Recognition. The power flow transmission path has spatiality in a spatial structure, and the intensive level of power distribution, magnitude of the peak value, and radiation effect of the power transition all have an effect on the transmission path recognition. A spatial structure can, therefore, be approximated using a 3D finite element model, and its nodes' power flow is calculated based on the power flow finite element method. When $\alpha=0.2 \sim$ 0.9 , DPTV $K_{\alpha}$ is calculated eight times separately, and eight transmission domains $\Gamma_{\alpha}$ are confirmed. The transmission intensity $P W_{\alpha}$ can then be obtained using

$$
P W_{\alpha}=\frac{\sum_{i=1}^{n_{\alpha}} p_{i} \Gamma_{i}}{\sum_{i=1}^{n_{\alpha}} \Gamma_{i}},
$$

where $P W_{\alpha}$ is the average power flow $(\mathrm{W}), p_{i}$ represents the power flow value at the $i$ th node of the finite element model, $\Gamma_{i}$ represents the volume of the $i$ th node with unit $\mathrm{m}^{3}$, and $n_{\alpha}$ stands for the total number of nodes in the transmission domain.

The Law of Dominant Path Recognition is as follows: $\beta_{\alpha}=$ $\Delta P W_{\alpha} / \Delta P W_{\alpha-0.1}$, where $\beta_{\alpha}$ is the transmission dominance ratio of the adjacent significance factor $\alpha$, and $\Delta P W_{\alpha}=$ $P W_{\alpha}-P W_{\alpha-0.1}$ is the power flow discrepancy in the adjacent significance factor $\alpha$. If $\beta_{\alpha} \in(1.0,1.5]$, the transmission region is defined as the ordinary transmission path; if $\beta_{\alpha} \epsilon$ $(1.5,2.0]$, the transmission region is defined as the domain transmission path; and if $\beta_{\alpha}>2.0$, the transmission region is defined as the absolute transmission path.

In fact, several vibration transmission paths exist at the same time in most projects. The dominant and absolute transmission paths are not only the objects of dynamic transmission recognition but also the critical paths for structural damping and isolation vibration.

\subsection{Method of Dimensionless Power Flow and Power Decay} Rate. The concept of insertion loss is involved in generalising the conclusion made in this section; therefore, the methods of Dimensionless Power Flow (DPF) and Power Decay Rate (PDR) are used to analyse the decrease in power on every vibration transmission path. The DPF and PDR can be described by (9) and (10), respectively, as follows:

$$
\begin{gathered}
d b=10 \log \left(\frac{p}{B_{\alpha}}\right) \\
\lambda=\frac{\left(d b_{i}-d b_{j}\right)}{\Delta L},
\end{gathered}
$$

where $d b$ is the DPF, $B_{\alpha}$ is a reference power flow value used instead of the DPTV $K_{\alpha}\left(\mathrm{W} / \mathrm{m}^{3}\right), \alpha$ is the significance factor of the dominant transmission, $\alpha=0.2 \sim 0.9, \lambda$ is the PDR $(\mathrm{db} / \mathrm{m}), d b_{i}$ and $d b_{j}$ are the DPFs between any two points, and $\Delta L$ is the corresponding distance $(\mathrm{m})$. The higher the value of $\lambda$ becomes, the more the energy has been absorbed, while a lower value indicates lower absorption and vibrations transmitted far from the powerhouse.

\section{Finite Element Model}

3.1. Finite Element Model and Load. The 3D finite element model of the main and auxiliary powerhouse, as shown in Figure 1, is established based on Hohhot Pump Storage Station, which has the main powerhouse, erection bay, and auxiliary powerhouse, and four hydroelectric generating sets are located on the main powerhouse and 22 meters distance at a line. Five floors from the lowest to the highest in the main powerhouse are draft tube floor, spiral case floor, turbine floor, generatrix floor, and generator floor, respectively. The auxiliary powerhouse nearby the main powerhouse has seven floors, including libraries, storerooms, and offices. The auxiliary powerhouse and the part of the main powerhouse with one hydroelectric generating set are chosen for researching on power transmission between the structures. For the main powerhouse, the floors, the walls, the generator supports, wind covers, spiral case, and draft tube are the main structures, and the thickness of the walls is 1.0 meter, the spiral case is made of steel, the diameter of the inlet pipeline is 2.0 meters, and the concrete thickness outside of the spiral case is from 0.8 meter to 2.0 meters. The draft tube belongs to elbow style, and the concrete thickness outside of the draft tube is 1.35 meters. The auxiliary powerhouse is separated from the main powerhouse by settlement joint; it has seven floors as shown in Figure 1. The walls of the main powerhouse and the concrete of draft tube are connected with rocks around the powerhouse, while peripheral columns 


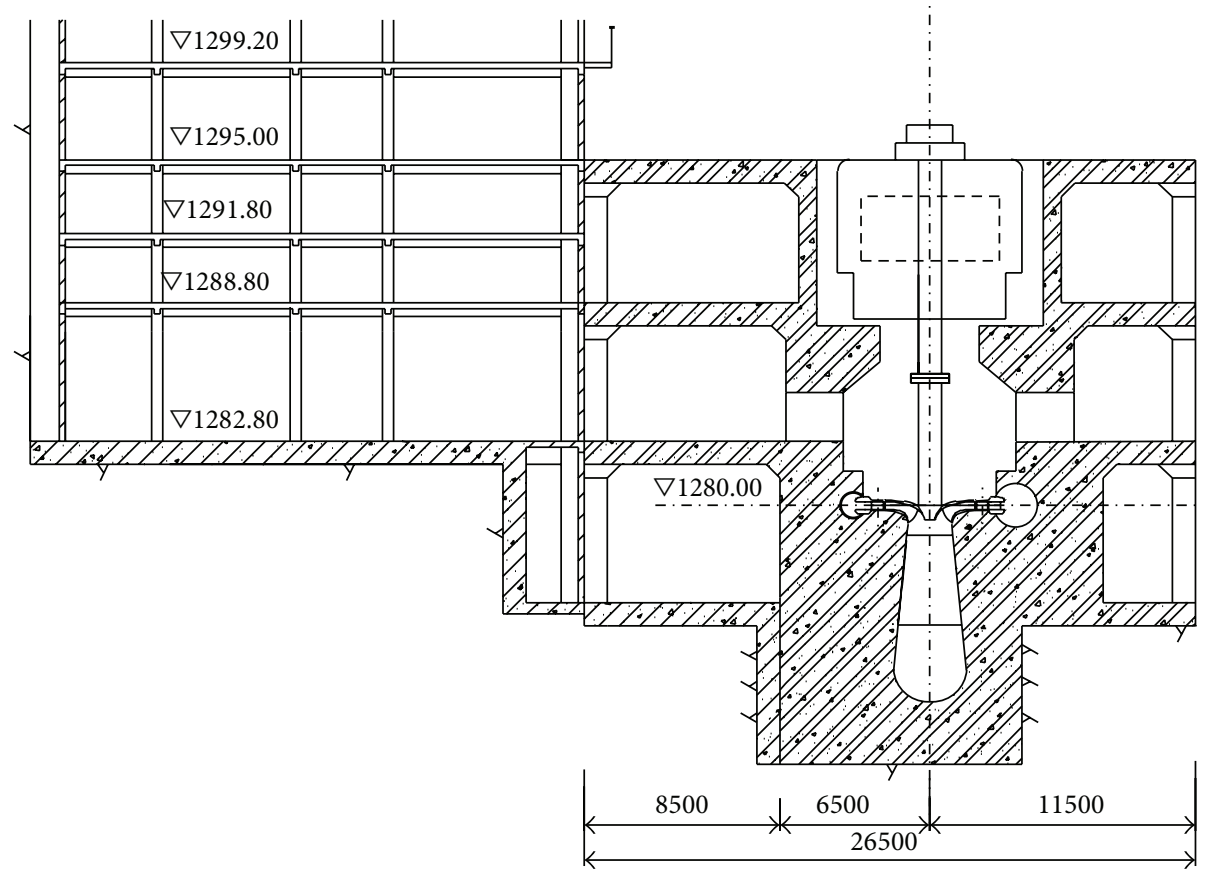

(a) Profile view of underground hydropower house

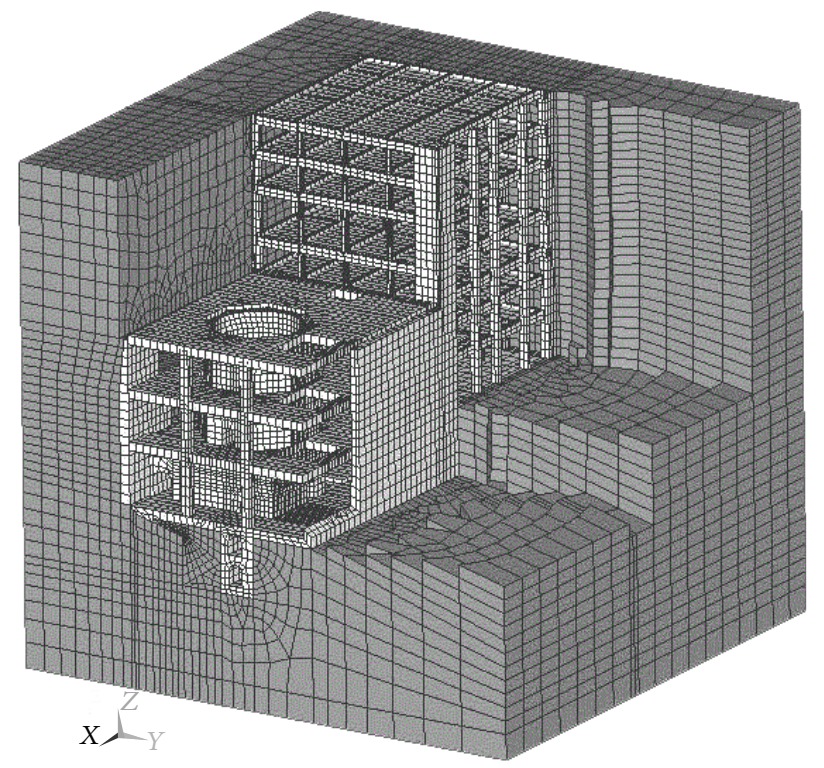

(b) FEM of underground hydropower house

FIgURE 1: Profile View and the FEM of underground hydropower house.

and the lowest floor of the auxiliary powerhouse are also connected with rocks nearby the structures.

The 3D finite element model of the main and auxiliary powerhouse, as shown in Figure 1, had 85448 nodes and 64971 elements, among which element solid45 was used for the concrete structure and surrounding rock, element shell63 was used for the steel liner and floors, element beam188 was used for the beams and columns in the construction, element link10 was used for the filler in structural joints (compression only), and element combin14 was used for the viscoelastic dynamic boundary. In the global coordinate system, the $X$ axis was perpendicular to the river and the positive direction pointed to the main powerhouse; the $Y$ axis ran along river and the positive direction pointed upstream; and the $Z$ axis was vertical with the positive direction pointing upwards.

As for the load for this research, fluctuating pressure was used by the numerical simulation analysis measured $0.153 \mathrm{MPa}$ at the entrance of the spiral case, assuming the same value on every inner surface of the steel liner. The dominant frequency was measured as approximately $75 \mathrm{~Hz}$ 


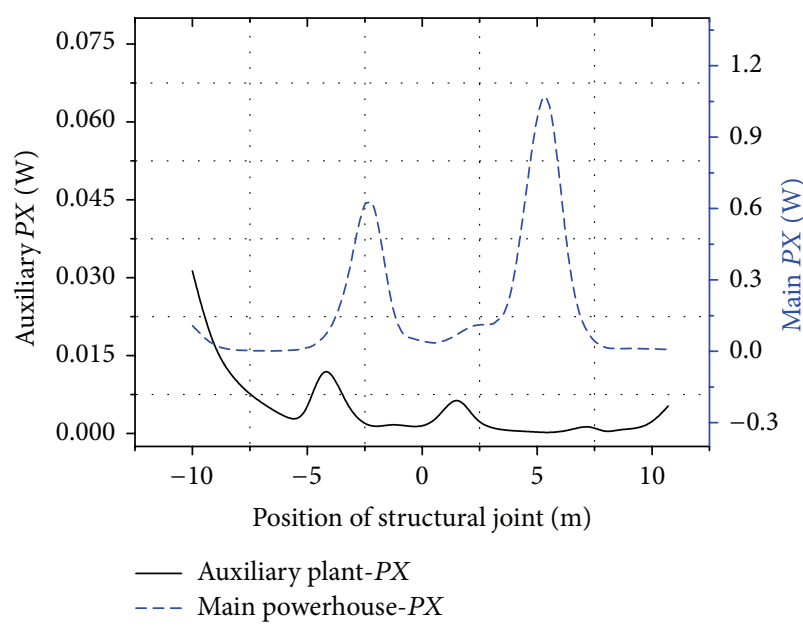

(a) Power flow transmission on $X$

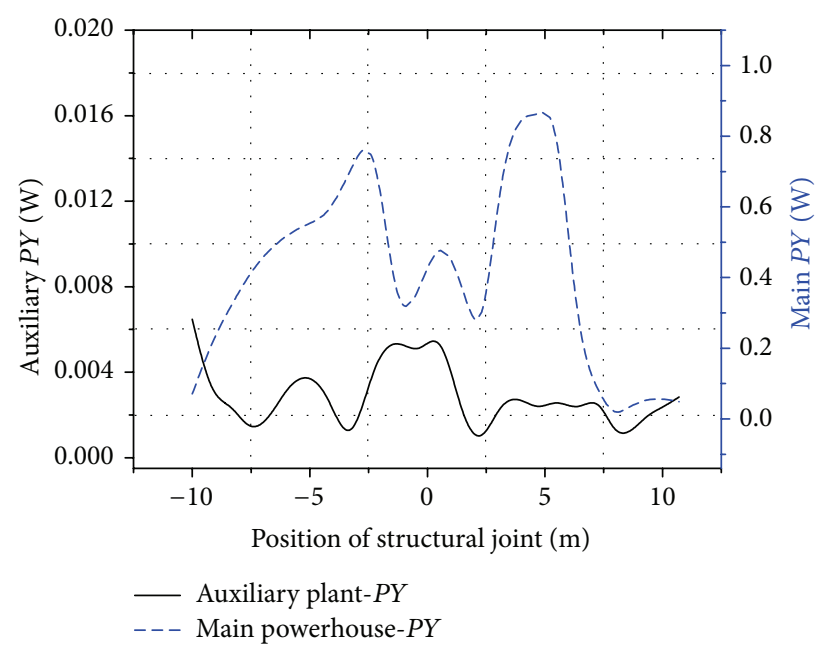

(b) Power flow transmission on $Y$

Figure 2: Dynamic transmission in structure joint at $1288 \mathrm{~m}$.

(multiplied by the turbine rotation frequency and the number of turbine blades). The dynamic model was calculated by the harmonic response analysis.

\subsection{Calculation Assumptions}

(1) The dynamic transmission characteristics were determined for a typical load (a harmonic load) and specific structure (underground hydropower house).

(2) In the 3D structure's interior (unrelated to the shell), the shear wave and longitudinal wave took on the role of conducting energy, while the flexible wave effect was negligible.

(3) The rock was assumed to have material isotropy and the joints between the rock and concrete structure were assumed to be elastic connections.

(4) The filler in the structural joints between the main and auxiliary powerhouses was a nonlinear material that was in compression but not in tension.

Based on the first assumption, the difference between the positive and negative power flows in the $3 \mathrm{D}$ structure was negligible, and the effective power flow value was accepted for its fluctuant theory. Based on the second assumption, three translation DOFs were used to estimate the vibration and transmission characteristics of the concrete and rock. Details about the vibration transmission of the floors (six DOFs) are available in our other paper.

\section{Analysis of Results}

In previous study [1], the transmission in the coupling structure, such as the main and auxiliary underground powerhouses, was confirmed as being filler in the structural joints and the foundation rock under the powerhouse. However, the amount of power that would be conducted by the rock or filler was not previously reported. Based on the power flow finite element method and the code of transmission path recognition, an analysis of the vibration transmission in the coupled main and auxiliary powerhouses yielded the following results.

4.1. Vibration Transmission Analysis of the Filler in Structural Joints. The conductivity of the filler in the system's structural joints was defined as the ratio of output power in the nodes located on the main powerhouse floor's boundary to the input power in the nodes located on the auxiliary powerhouse floor's boundary. The conductivity of different fillers (asphalt wood plate, rubber plate, and closed-cell foam plate) is always less than $10 \%$. A closed-cell foam plate was chosen as the fill material for the structural joints in this study [1], and the power flow solution for the nodes located on the structural joint at $1288.0 \mathrm{~m}$ between the main and auxiliary powerhouse floors is shown in Figure 2. It was obvious that the power flow peak on the main powerhouse side was located near the columns of the floor boundary but did not have a uniform distribution. The power flow peak was located near the downstream wall on the auxiliary powerhouse side not along the filler. The conductivity of the structural filler was less than 3\%, and neither curve was consistently at the same location, as shown in Figures 2(a) and 2(b). Therefore, it was concluded that the structural joint and filler could perfectly isolate structural vibrations, and the filler's power transmission (considering a closed-cell foam plate) could be neglected.

The power threshold values of the auxiliary powerhouse at $1288.8 \mathrm{~m}$ were calculated using (8) and are listed in Table 1. By comparing each threshold value, we observed that the power flow perpendicular to and along the river was clearly higher than that in the vertical direction. This phenomenon indicated that the power flow in the floors was conducted mainly in the horizontal direction, while the vertical power flow had a small amplitude and decayed quickly. As for the dominant power transmission in the auxiliary powerhouse 
TABLE 1: DPTV of the auxiliary powerhouse floor at $1288.8 \mathrm{~m}$. Units: W.

\begin{tabular}{|c|c|c|c|c|c|c|c|}
\hline \multirow{2}{*}{ Factor $\alpha$} & \multicolumn{2}{|c|}{ Perpendicular to the river $(X)$} & \multicolumn{2}{|c|}{ Along the river $(Y)$} & \multicolumn{2}{|c|}{ Vertical direction $(Z)$} & \multirow{2}{*}{ Remark } \\
\hline & $K_{\alpha}$ & $\beta_{\alpha}$ & $K_{\alpha}$ & $\beta_{\alpha}$ & $K_{\alpha}$ & $\beta_{\alpha}$ & \\
\hline$\alpha=0.6$ & $1.8 E-3$ & 1.31 & $2.5 E-3$ & 1.24 & $0.4 E-3$ & 1.33 & \multirow{4}{*}{$\begin{array}{l}\alpha \text { is ignored when } \\
\alpha=0.2 \sim 0.5\end{array}$} \\
\hline$\alpha=0.7$ & $2.6 E-3$ & 1.38 & $3.3 E-3$ & 1.23 & $0.6 E-3$ & 1.42 & \\
\hline$\alpha=0.8$ & $\underline{4 E-3}$ & $\underline{1.58}$ & $4.5 E-3$ & 1.38 & $\underline{0.9 \mathrm{E}-3}$ & $\underline{1.65}$ & \\
\hline$\alpha=0.9$ & $6.7 E-3$ & 2.23 & $\underline{5.7 E-3}$ & $\underline{1.82}$ & $1.5 E-3$ & 2.19 & \\
\hline
\end{tabular}

TABLE 2: DPTV of the rock. Units: W.

\begin{tabular}{|c|c|c|c|c|c|c|c|}
\hline \multirow{2}{*}{ Height and $\alpha$} & \multicolumn{2}{|c|}{ Perpendicular to the river $(X)$} & \multicolumn{2}{|c|}{ Along the river $(Y)$} & \multicolumn{2}{|c|}{ Vertical direction $(Z)$} & \multirow{2}{*}{ Remark } \\
\hline & $K_{\alpha}$ & $\beta_{\alpha}$ & $K_{\alpha}$ & $\beta_{\alpha}$ & $K_{\alpha}$ & $\beta_{\alpha}$ & \\
\hline \multicolumn{8}{|l|}{$1269.0 \mathrm{~m}$} \\
\hline$\alpha=0.7$ & 0.0004 & 1.472 & 0.0005 & 1.3585 & 0.001 & 1.4234 & \multirow{3}{*}{$\begin{array}{l}\text { The first floor nearby } \\
\text { the draft tubes }\end{array}$} \\
\hline$\alpha=0.8$ & $\underline{0.0006}$ & 1.6309 & 0.0007 & 1.4798 & 0.0014 & 1.4941 & \\
\hline$\alpha=0.9$ & 0.0012 & 1.8778 & $\underline{0.0011}$ & 1.5385 & 0.0023 & 2.0099 & \\
\hline \multicolumn{8}{|l|}{$1273.0 \mathrm{~m}$} \\
\hline$\alpha=0.7$ & 0.001 & 1.2925 & 0.0009 & 1.3936 & 0.0014 & 1.3935 & \multirow{3}{*}{$\begin{array}{l}\text { The second floor } \\
\text { nearby the draft tubes }\end{array}$} \\
\hline$\alpha=0.8$ & 0.0015 & 1.4358 & $\underline{0.0013}$ & 1.5735 & $\underline{0.0023}$ & 1.5255 & \\
\hline$\alpha=0.9$ & 0.0025 & 1.4142 & 0.0027 & 1.5965 & 0.0041 & 1.9193 & \\
\hline \multicolumn{8}{|l|}{$1275.8 \mathrm{~m}$} \\
\hline$\alpha=0.7$ & 0.0008 & 1.4514 & 0.0007 & 1.37 & 0.0011 & 1.4969 & \multirow{3}{*}{$\begin{array}{l}\text { The third floor nearby } \\
\text { the spiral cases }\end{array}$} \\
\hline$\alpha=0.8$ & $\underline{0.001}$ & 1.7067 & 0.001 & 1.393 & $\underline{0.0019}$ & 1.6826 & \\
\hline$\alpha=0.9$ & 0.0015 & 2.3985 & $\underline{0.0014}$ & 1.7017 & 0.003 & 2.4476 & \\
\hline \multicolumn{8}{|l|}{$1282.8 \mathrm{~m}$} \\
\hline$\alpha=0.7$ & 0.0036 & 1.3079 & 0.0038 & 1.2554 & 0.0019 & 1.2966 & \multirow{3}{*}{$\begin{array}{l}\text { The fourth floor } \\
\text { nearby the turbine }\end{array}$} \\
\hline$\alpha=0.8$ & $\underline{0.0048}$ & 1.5584 & 0.005 & 1.431 & $\underline{0.0026}$ & 1.5207 & \\
\hline$\alpha=0.9$ & $\overline{0.0074}$ & 1.8851 & $\underline{0.0069}$ & 1.7212 & 0.0037 & 2.0477 & \\
\hline \multicolumn{8}{|l|}{$1288.8 \mathrm{~m}$} \\
\hline$\alpha=0.7$ & 0.0047 & 1.2785 & 0.0025 & 1.3129 & 0.0023 & 1.4352 & \multirow{3}{*}{$\begin{array}{l}\text { The fifth floor nearby } \\
\text { the generatrix cables }\end{array}$} \\
\hline$\alpha=0.8$ & 0.0065 & 1.308 & 0.003 & 1.4138 & 0.0037 & 1.3578 & \\
\hline$\alpha=0.9$ & $\underline{0.0087}$ & 1.6645 & $\underline{0.0036}$ & 2.2874 & 0.0056 & 1.4485 & \\
\hline \multicolumn{8}{|l|}{$1295.0 \mathrm{~m}$} \\
\hline$\alpha=0.7$ & $\underline{0.007}$ & 1.5799 & $\underline{0.0034}$ & 1.7096 & $\underline{0.005}$ & 1.7021 & \multirow{3}{*}{$\begin{array}{l}\text { The sixth floor nearby } \\
\text { the generator sets }\end{array}$} \\
\hline$\alpha=0.8$ & $\overline{0.0112}$ & 1.6649 & $\overline{0.005}$ & 1.8397 & $\overline{0.007}$ & 1.8457 & \\
\hline$\alpha=0.9$ & 0.0186 & 2.4219 & 0.0148 & 2.6641 & 0.011 & 2.7651 & \\
\hline
\end{tabular}

floors, the significance factor, $\alpha$, corresponding to the DPTV (expressed in a bold font with an underline in the table), was greater than 0.7 , which meant that the transmission region of the dominant power was most likely concentrated.

4.2. Analysis of the Rock's Vibration Transmission. As mentioned above, the surrounding rock played an important role in the vibration transmission through the main and auxiliary powerhouse. Therefore, the vibration transmission of the rocks located at the bottom of and surrounding the powerhouse required further analysis. Based on the FEM in Figure 1, the DPTV in rock was calculated at six positions from $1269.0 \mathrm{~m}$ to $1295.0 \mathrm{~m}$, and the solutions are listed in Table 2.
The concrete around the spiral case connected the rock downstream of the main powerhouse, located from $1275.8 \mathrm{~m}$ to $1282.8 \mathrm{~m}$, and the dynamic transmission was higher here than in other regions. From Figure 3, we concluded that the power transmission in the rock receded gradually when the height increased. The core vibration energy focused on the dominant transmission path and decreased gradually during its conductance. The rock from $1282.0 \mathrm{~m}$ to $1295.0 \mathrm{~m}$ had a higher power threshold value than that in other locations, indicating the dynamic transmission's obvious effect. The region corresponded to the auxiliary powerhouse's first through third floors because the main powerhouse was located between the turbine and generator set floors. The DPTA of the rock below $1275.8 \mathrm{~m}$ was less than $3 \times 10^{-3} \mathrm{~W}$, and the fluctuation was inconspicuous. Therefore, the dynamic 


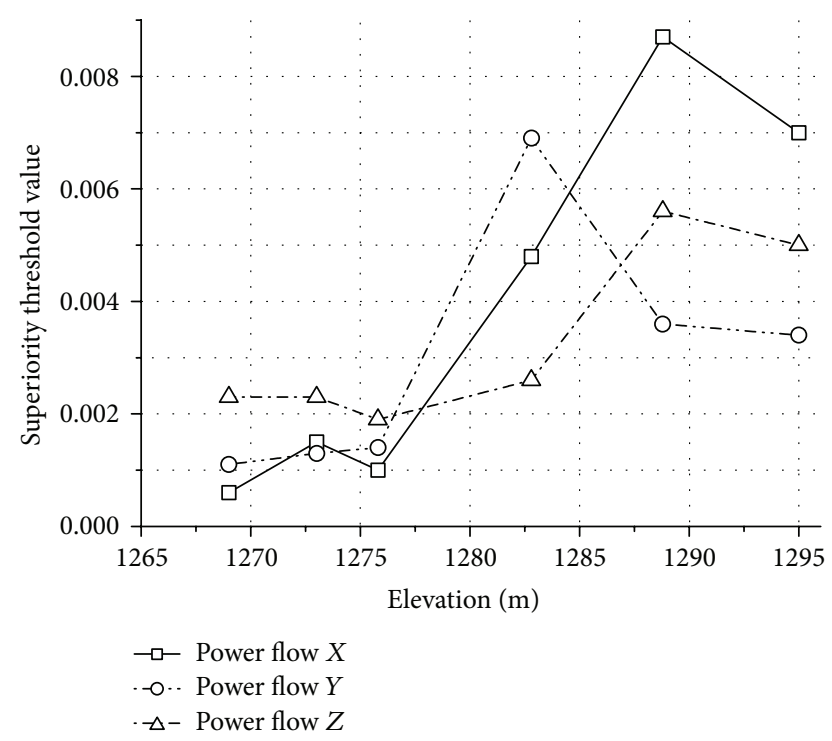

Figure 3: DPTV distribution.

transmission in the rock was stable, with a low power flow amplitude (as in the region between $1269.0 \mathrm{~m}$ and $1275.8 \mathrm{~m}$ ). Due to the vibration decay in the concrete and rock, which was created by the fluctuating pressure from the spiral case and draft tube, the DPTV distribution curves for distances far from the spiral case concrete are not drawn in Figure 3.

It should be noted that the dominant transmission path must exist because of the DPTV during the vibration transmission, and the path distributes in belts corresponding to the DPTV. Taking the section from $1269.0 \mathrm{~m}$ to $1288.8 \mathrm{~m}$ as an example, the dominant transmission path distribution of the two heights is drawn in Figure 4. Figure 4(a) represents the foundation rock transmission and Figure 4(b) represents the foundation of the surrounding rock.

(1) Dominant Transmission Path of Rock at $1269.0 \mathrm{~m}$. The directions of dynamic transmission for the foundation rock were divided into three parts, perpendicular to the river, along the river, and in vertical direction. Figure 4(a) shows the dominant transmission distribution in the direction perpendicular to the river. Using (10), its power decay rate was less than $0.62 \mathrm{db} / \mathrm{m}$ along the $Y$ axis and approximately $1.08 \mathrm{db} / \mathrm{m}$ along the $X$ axis. It was clear that the foundation rock had a finite boundary for vibration transmission, and approximately 20 percent of the rock under the auxiliary was affected by the vibration from the spiral case concrete and induced structural vibration in the auxiliary powerhouse. The main transmission path ran from the foundation rock of the main powerhouse to the up- or downstream rock in the direction perpendicular to the river. The vibration transmitted away from the powerhouse, which could be helpful for vibration isolation.

The dominant transmission path in the direction along the river was similar to that in the perpendicular direction; therefore, the figure is not provided here. This path's vertical transmission curves are presented in Figure 4(b), and the main transmission path ran from the foundation rock of the main powerhouse to the downstream rock in the $Y$ direction. The power decay rate was less than $0.38 \mathrm{db} / \mathrm{m}$, and the power transmitted away from the powerhouse with obvious volatility. However, the power decay rate in the $X$ direction was approximately $0.77 \mathrm{db} / \mathrm{m}$, and the region of influence was approximately 20 percent of the auxiliary powerhouse.

Therefore, regardless of the direction of transmission, the decay transmission in the auxiliary powerhouse's foundation rock was clear, and the dominant transmission region could not exceed 20 percent of the auxiliary powerhouse.

(2) Dominant Transmission Path of Rock at $1288.8 \mathrm{~m}$. According to Figure 3, the DPTVs in three directions at $1288.8 \mathrm{~m}$ were greater than others in the system; therefore, this dominant transmission path could be considered to have typical properties representing the dynamic transmission behaviour of rock surrounding the auxiliary powerhouse. Figure 5(a) shows the dominant transmission distribution in the direction perpendicular to the river, with a DPTV of $8.7 \times 10^{-3} \mathrm{~W}$, and a transmission path running along the downstream wall of the main powerhouse to the downstream rock, with a thickness of $2 \mathrm{~m}$, and to the floor boundary of the auxiliary powerhouse, with a power decay rate of $0.95 \mathrm{db} / \mathrm{m}$. Figure 5(b) shows the dominant transmission distribution in the direction along the river, with a DPTV of $3.6 \times 10^{-3} \mathrm{~W}$, and a transmission path that runs along the downstream wall of the main powerhouse to downstream rocks, with a thickness of $10 \mathrm{~m}$, and to the floor boundary of the auxiliary powerhouse, with a power decay rate of $0.6 \mathrm{db} / \mathrm{m}$.

Because there were no DPTVs in the vertical direction, the vibration transmission was simply an ordinary transmission; therefore, a figure is not provided here. The path could have run through the main powerhouse to up- or downstream rock, with little vibration power transmitted to the auxiliary powerhouse.

In short, the dominant vibration path ran from the downstream wall of the main powerhouse, along downstream rock, to the floor of the auxiliary powerhouse at $1288.8 \mathrm{~m}$. Above all, the power flow in the direction along the river was superior to that perpendicular to the river, and the vertical vibrations were not transmitted to the auxiliary powerhouse by the surrounding rock.

\section{Conclusions}

A unified main and auxiliary powerhouse structure is popular in underground hydropower engineering; therefore, the laws of vibration transmission are beneficial to the structural optimisation of such systems. Due to this study's limitations, only portions of the power flow and the transmission paths in special positions were analysed. However, the conclusions drawn from the results reflected the general laws of vibration transmission for underground powerhouses.

(1) The filler in the structural joints between the main and auxiliary powerhouses had an effect on structural vibration transmission, but the close-cell foam plane actively isolated the vibration on both sides of 


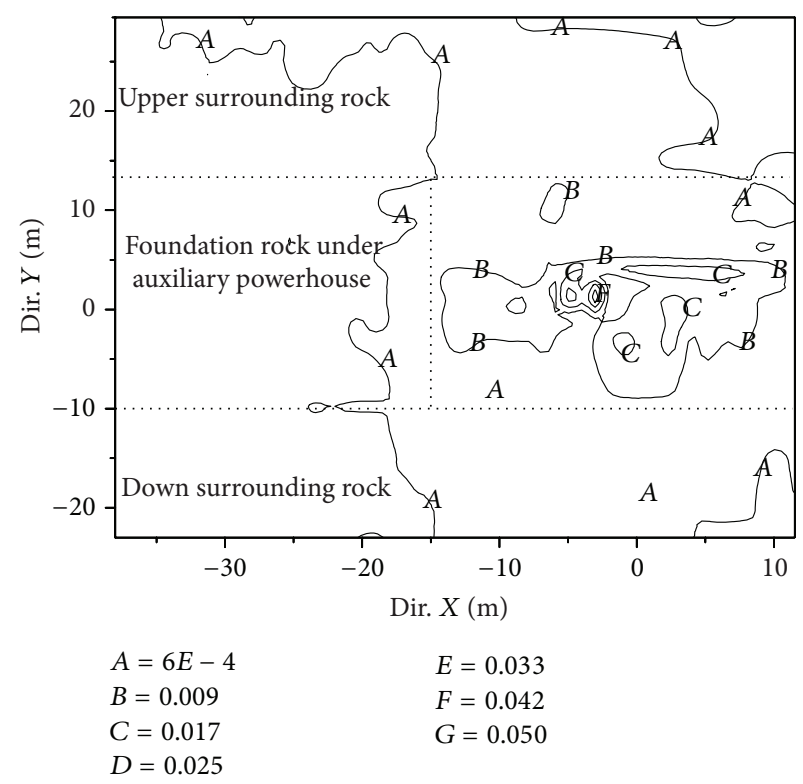

(a) Dominant transmission distribution in direction perpendicular to the river

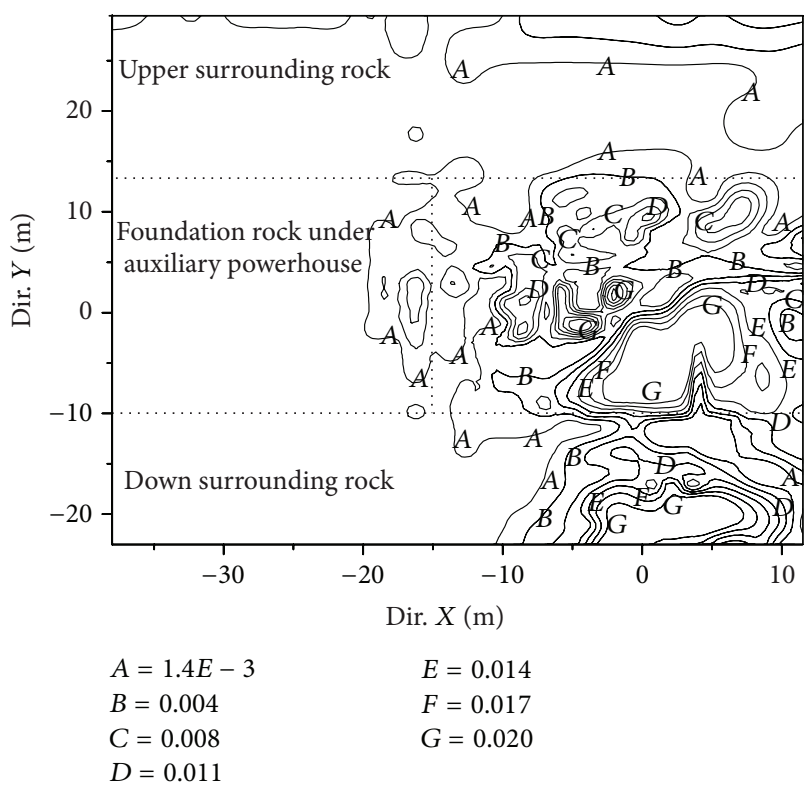

(b) Dominant transmission distribution in the vertical direction

FIGURE 4: Dominant transmission path at $1269.0 \mathrm{~m}$.

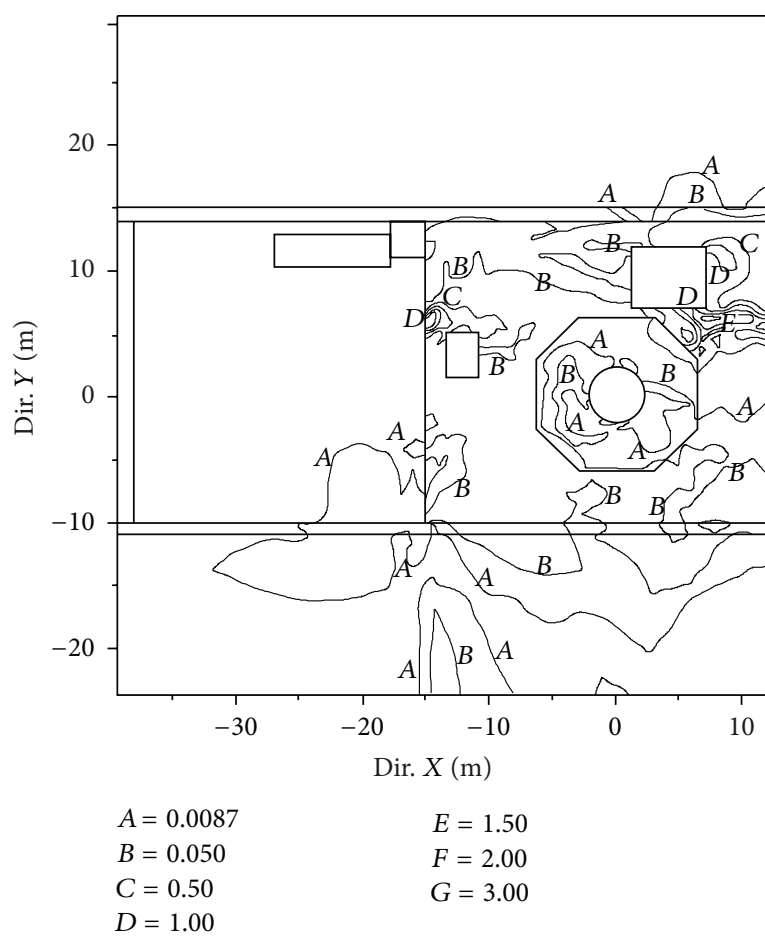

(a) Dominant transmission distribution in direction along the river

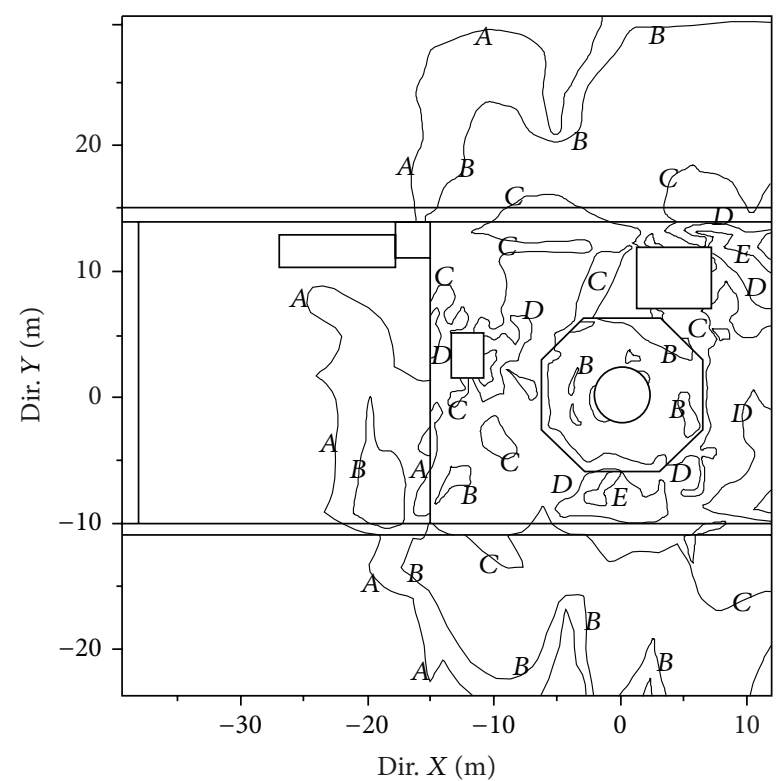

$$
\begin{array}{ll}
A=0.0036 & E=1.00 \\
B=0.01 & F=1.50 \\
C=0.10 & G=2.00 \\
D=0.50 &
\end{array}
$$

(b) Dominant transmission distribution in direction perpendicular to the river

FiguRE 5: Dominant transmission path at $1288.8 \mathrm{~m}$.

the structural joints, making it a remarkable structural filling.

(2) In our analysis of the auxiliary powerhouse's foundation rock, the dynamic transmission in the vertical direction and that along the river were more obvious than that in the direction perpendicular to the river. Approximately 20 percent of the auxiliary powerhouse's foundation rock was disturbed by the vibrations coming from the main powerhouse. The first 
floor of the auxiliary powerhouse was significantly affected by the foundation rock, while the other floors were not.

(3) On higher floors, the power came from downstream rock at the same elevation in the directions along and perpendicular to the river. The columns transmitted only vertical power flow, and the power transmission in these floors clearly decreased with increasing elevation.

(4) As for hydropower house damping vibration and isolation vibration, two aspects should be considered: extending the path and cutting off the path. As for foundation rock, the distance from spiral case concrete to auxiliary powerhouse foundation should be extended but, for surrounding rock, the method of cutting off the transmission path can be adopted, such as cutting off the connection of rock and auxiliary powerhouse walls and the columns, as well as the floors.

\section{Conflict of Interests}

The authors declare that there is no conflict of interests regarding the publication of this paper.

\section{Acknowledgment}

This work was supported by the National Natural Science Foundation of China (Grant no. 51379030).

\section{References}

[1] W. Xu, X. Y. Xu, and Z. Y. Ma, "Analysis on vibration conductivity in walls of hydropower house based on power flow theory," Advanced Materials Research, vol. 424-425, pp. 285-289, 2012.

[2] J. Wu, H. X. Zhang, Z. M. Kou, and C. Lu, "Numerical simulation on dynamic analysis for pipe vibration control based on an actively generated hydraulic excitation force," Advanced Materials Research, vol. 490-495, pp. 2328-2332, 2012.

[3] Z. Q. Tian, Y. L. Zhang, Z. Y. Ma, and J. Chen, "Effect of concrete cracks on dynamic characteristics of powerhouse for giant-scale hydrostation," Transactions of Tianjin University, vol. 14, no. 4, pp. 307-312, 2008.

[4] C.-H. Zhang and Y.-L. Zhang, "Nonlinear dynamic analysis of the Three Gorge Project powerhouse excited by pressure fluctuation," Journal of Zhejiang University: Science A, vol. 10, no. 9, pp. 1231-1240, 2009.

[5] S.-K. Lee, K.-S. Park, M.-S. Lee, K.-R. Rho, J.-S. Sim, and J.-H. Kim, "Vibrational power flow and its application to a passenger car for identification of vibration transmission path," SAE Technical Paper 2001-01-1451, 2001.

[6] S.-K. Lee, "Identification of a vibration transmission path in a vehicle by measuring vibrational power flow," Proceedings of the Institution of Mechanical Engineers Part D: Journal of Automobile Engineering, vol. 218, no. 2, pp. 167-175, 2004.

[7] A. H. Vander, P. Mas, and S. Dom, "Transfer path analysis in the critical path of vehicle refinement: the role of fast, hybrid and operational path analysis," in Proceedings of the SAE Noise and Vibration Conference and Exhibition, pp. 1-5, St. Charles, Ill, USA, 2007.

[8] D. De Klerk and D. J. Rixen, "Component transfer path analysis method with compensation for test bench dynamics," Mechanical Systems \& Signal Processing, vol. 24, no. 6, pp. 16931710, 2010.

[9] A. Le Bot and E. Bou Chakra, "Measurement of friction noise versus contact area of rough surfaces weakly loaded," Tribology Letters, vol. 37, no. 2, pp. 273-281, 2010.

[10] J. M. Renno and B. R. Mace, "Calculation of reflection and transmission coefficients of joints using a hybrid finite element/wave and finite element approach," Journal of Sound \& Vibration, vol. 332, no. 9, pp. 2149-2164, 2013.

[11] C. Wang, W. Gao, C. Song, and N. Zhang, "Stochastic interval analysis of natural frequency and mode shape of structures with uncertainties," Journal of Sound \& Vibration, vol. 333, no. 9, pp. 2483-2503, 2014.

[12] J. You, H.-G. Li, and G. Meng, "Validity investigation of random energy flow analysis for beam structures," Shock and Vibration, vol. 18, no. 1-2, pp. 269-280, 2011.

[13] Y. Liu, W. Li, X. Yang et al., "Vibration response and of a flexible manipulator with a moving base," Shock and Vibration, vol. 2015, Article ID 589507, 8 pages, 2015.

[14] S. J. Kim, S. G. Kim, K. S. Oh, and S. K. Lee, "Excitation force analysis of a powertrain based on CAE technology," International Journal of Automotive Technology, vol. 9, no. 6, pp. 703-711, 2008.

[15] R. Huo, Q. Wang, L. Zhang, and Y. Q. Zhou, "Research on optimization design of complex frame structure based on the power flow transmission target," Advanced Materials Research, vol. 538-541, pp. 2767-2771, 2012.

[16] H. J. Lee and K. J. Kim, "Vibrational power path analysis with rotational terms included and its application to compressor system," Transactions of the Korean Society for Noise and Vibration Engineering, vol. 15, no. 3, pp. 280-289, 2005.

[17] Y. S. Kim, E. Y. Kim, and S.-K. Lee, "Strategy for vibration reduction of a centrifugal turbo blower in a fuel cell electric vehicle based on vibrational power flow analysis," Proceedings of the Institution of Mechanical Engineers Part D: Journal of Automobile Engineering, vol. 224, no. 8, pp. 985-995, 2010.

[18] B. Zhi and Z. Y. Ma, "Disturbance analysis of hydropower station vertical vibration dynamic characteristics: the effect of dual disturbances," Structural Engineering and Mechanics, vol. 53, no. 2, pp. 297-309, 2015.

[19] B. Zhi and Z. Ma, "Path transmissibility analysis considering two types of correlations in hydropower stations," Journal of Applied Mathematics, vol. 2013, Article ID 802546, 9 pages, 2013.

[20] W. Xu, Z. Y. Ma, and C. H. Zhang, "Research on nonlinear simulation of spiral case in high head hydropower station," Advanced Materials Research, vol. 204-210, pp. 1904-1909, 2011. 


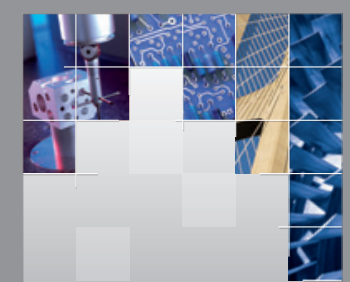

\section{Enfincering}
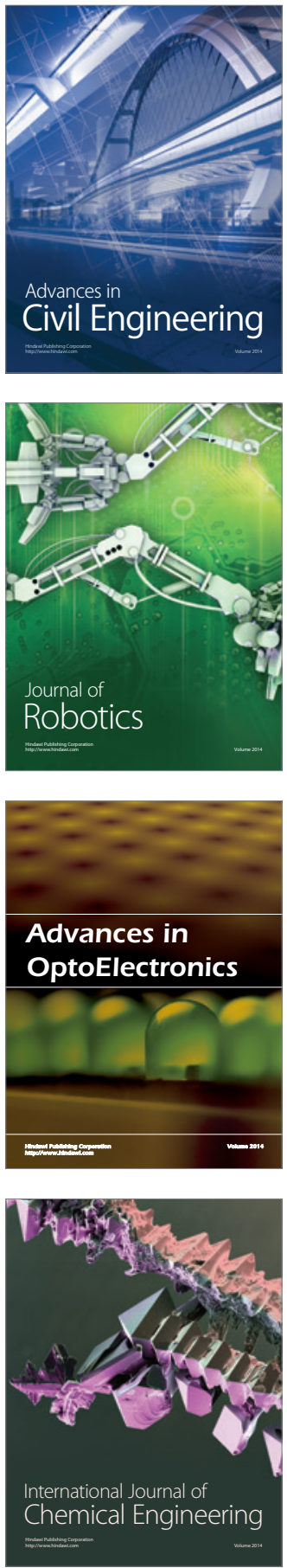

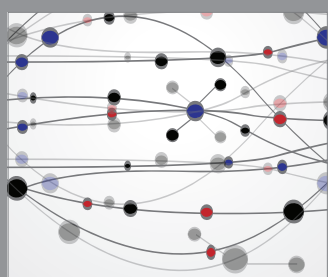

The Scientific World Journal

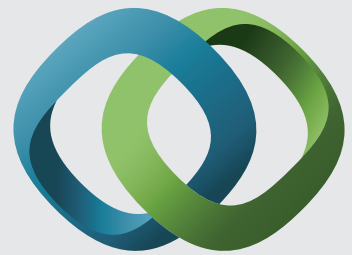

\section{Hindawi}

Submit your manuscripts at

http://www.hindawi.com
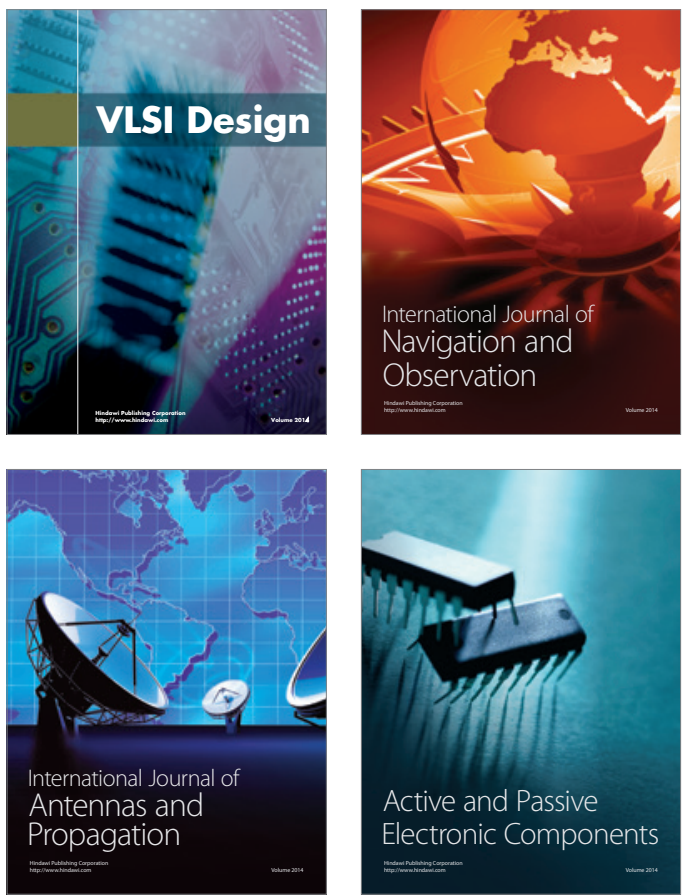
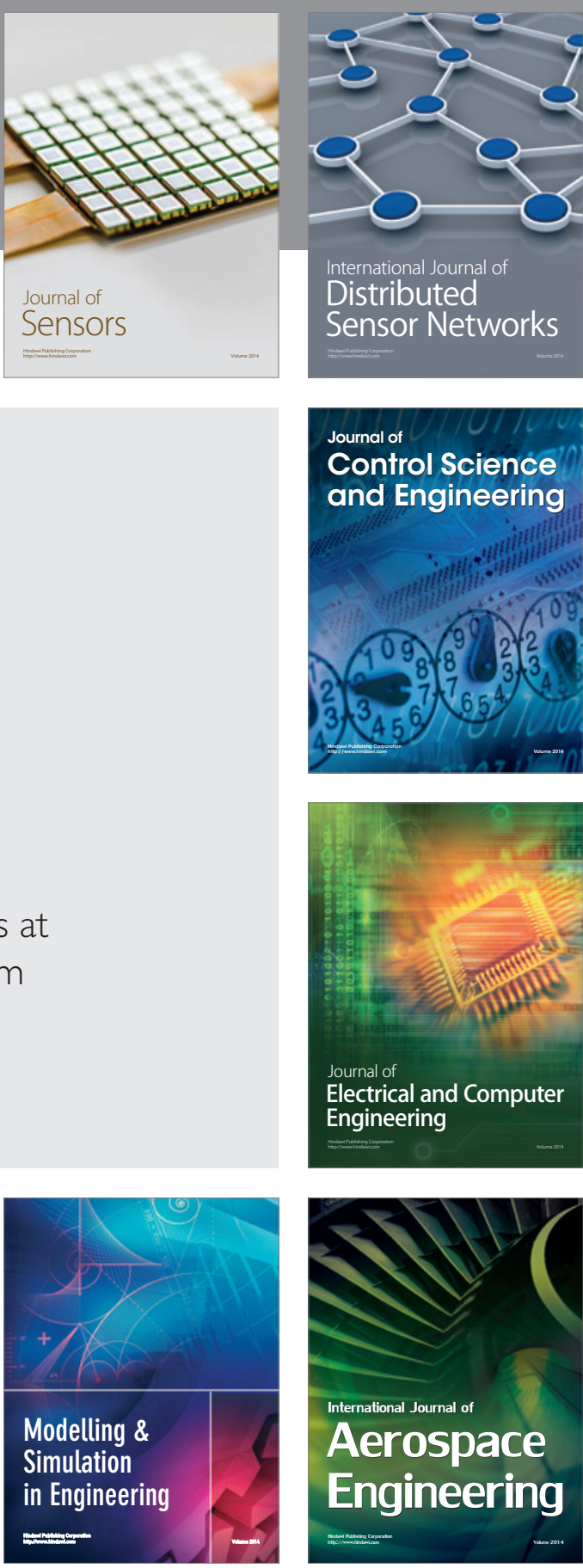

International Journal of

Distributed

Sensor Networks

Journal of

Control Science

and Engineering
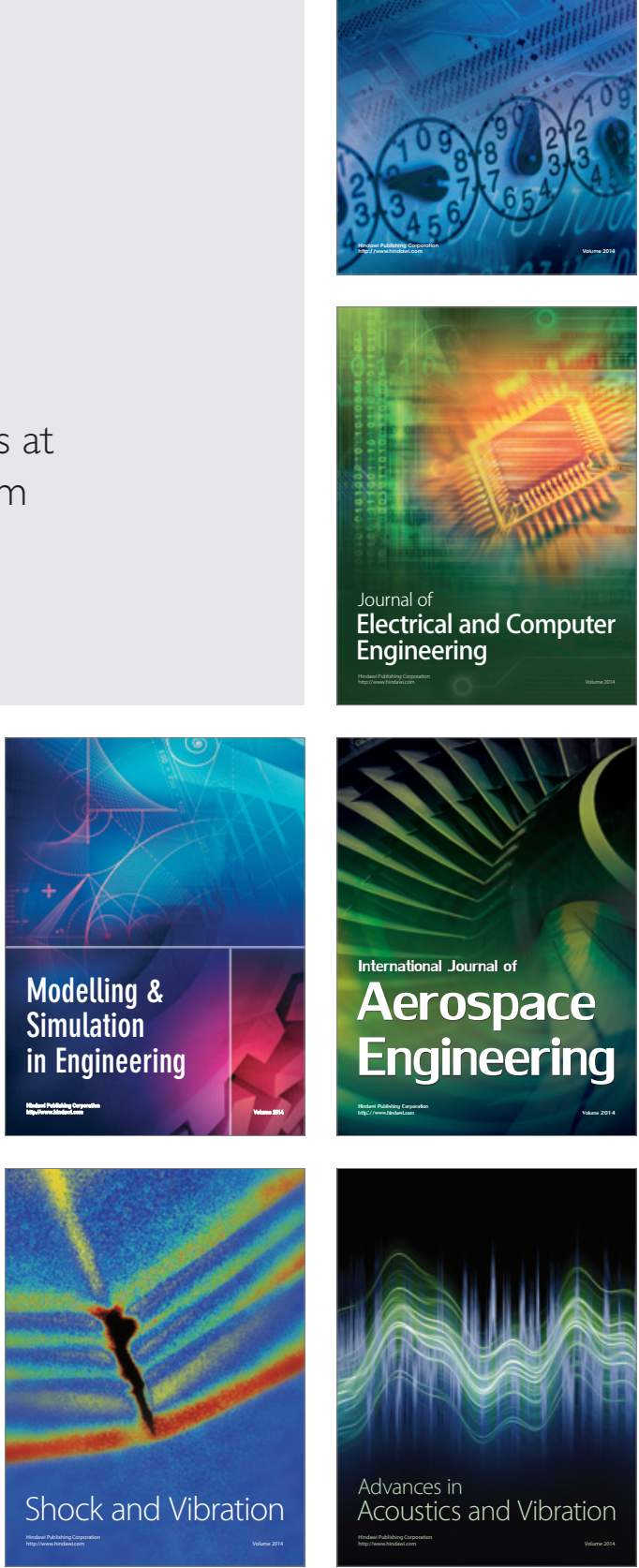